\title{
Bronchioloalveolar carcinoma with bronchorrhoea treated with erythromycin
}

\author{
T. Suga*, Y. Sugiyama*, T. Fujii**, S. Kitamura*
}

Bronchioloalveolar carcinoma with bronchorrhoea treated with erythromycin. T. Suga, Y. Sugiyama, T. Fujii, S. Kitamura. CERS Journals Ltd 1994.

ABSTRACT: Recent reports have shown that erythromycin inhibits bronchial hypersecretion, and, accordingly, erythromycin was administered to a patient with bronchioloalveolar carcinoma with bronchorrhoea.

After administration of erythromycin, marked reduction in the volume of sputum was observed, and the patient's quality of life was improved.

It is concluded that erythromycin may reduce hypersecretion in bronchioloalveolar carcinoma.

Eur Respir J, 1994, 7, 2249-2251.

Recent reports have indicated that erythromycin inhibits bronchial hypersecretion in patients with bronchial asthma and bronchorrhoea and from some cell lines [1-3]. On the basis of these observations, we administered erythromycin for the treatment of bronchorrhoea in a patient with bronchioloalveolar carcinoma (BAC).

\section{Case report}

In September 1990, a 65 year old male photographer with cough and dyspnoea was admitted to our institution. He had a 40 year history of smoking 20 cigarettes $\cdot$ day $^{-1}$. Coughing had gradually become more marked during the previous 2 month period, and was accompanied by expectoration of a large volume of watery white sputum. The patient had noticed unexplained weight loss of $8 \mathrm{~kg}$ during the same period, and dyspnoea on exertion during the last month.

Physical examination revealed moderate respiratory distress. Body temperature was $36^{\circ} \mathrm{C}$; pulse 84 beats. $\mathrm{min}^{-1}$; respiratory rate, 30 breaths $\cdot \mathrm{min}^{-1}$; arterial blood pressure, $160 / 80 \mathrm{mmHg}$. Crackles and rhonchi were heard in the bilateral lower lung fields. The findings for the abdomen and extremities, and neurological examination were all normal. Chest roentgenogram revealed alveolar infiltrates involving mainly the bilateral lower lobes (fig. 1). Analysis of arterial blood gases in room air revealed $\mathrm{pH}$ of 7.45 , arterial oxygen tension $\left(\mathrm{PaO}_{2}\right) 44.6$ $\mathrm{mmHg}(5.9 \mathrm{kPa})$, and arterial carbon dioxide tension $\left(\mathrm{PaCO}_{2}\right) 37.9 \mathrm{mmHg}(5.1 \mathrm{kPa})$.

Further investigation revealed a haemoglobin concentration of $19.0 \mathrm{~g} \cdot \mathrm{dl}^{-1}$ (normal range, $13.5-17.6 \mathrm{~g} \cdot \mathrm{dl}^{-1}$ ), with normal total and differential white blood cell count and platelet count, decreased serum total protein of 5.9 $\mathrm{g} \cdot \mathrm{dl}^{-1}$ (normal range $6.4-7.8 \mathrm{~g} \cdot \mathrm{dl}^{-1}$ ), and increased serum
Depts of *Pulmonary Medicine and **Pathology, Jichi Medical School, Minamikawachi-machi, Tochigi, Japan.

Correspondence: Y. Sugiyama, Dept of Pulmonary Medicine, Jichi Medical School, Minamikawachi-machi, Tochigi, 329-04 Japan.

Keywords: Bronchioloalveolar carcinoma, bronchorrhea, erythromycin, hypersecretion

Received: April 121994

Accepted after revision June 211994

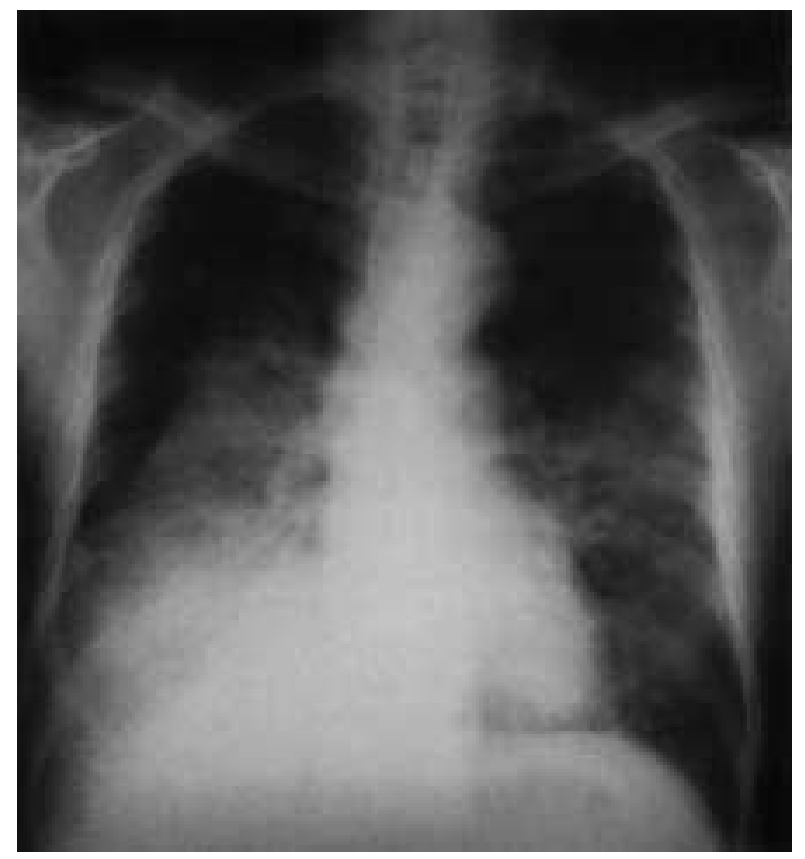

Fig. 1. - Chest roentgenogram of the patient showing alveolar infiltrates involving mainly the bilateral lower lobes.

carcinoembryonic antigen level of $18.8 \mathrm{ng} \cdot \mathrm{ml}^{-1}$, (normal $\left.<5.0 \mathrm{ng} \cdot \mathrm{ml}^{-1}\right)$.

The clinical course of the patient is presented in figure 2. Sputum was routinely stored in a graduated cup, and the volume of sputum was measured and recorded every day. Although administration of prednisolone $(60 \mathrm{mg})$ was initiated because the $\mathrm{PaO}_{2}$ level whilst breathing of $50 \% \mathrm{O}_{2}$ was less than $60 \mathrm{mmHg}(8 \mathrm{kPa})$, the hypoxaemia did not improve. The patient was diagnosed as having BAC based on the cytological findings of his sputum and other clinical findings. 
1990

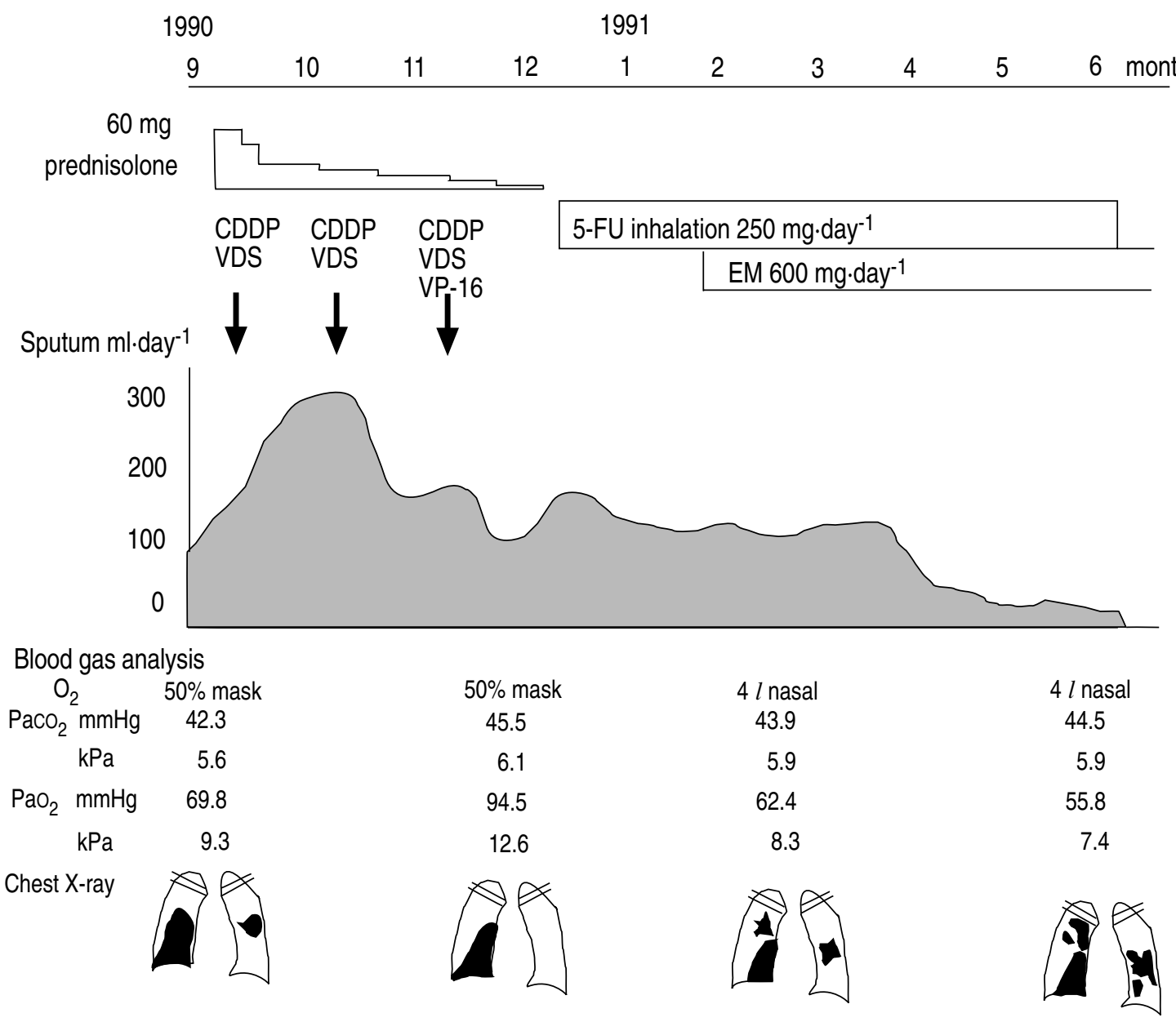

Fig. 2. - The clinical course of the patient. Sputum volume was significantly decreased after 10 weeks of administration of erythromycin. CDDP: cisplatin; VDS: vindesine; VP-16: etoposide; 5-FU: 5-fluorouracil; EM: erythromycin.

Following initial administration of chemotherapy consisting of cisplatin (CDDP) and vindesine (VDS), slight and transient improvement of arterial blood gases was seen. Sputum volume increased, thereafter, to almost $300 \mathrm{ml} \cdot \mathrm{day}^{-1}$. A second course of chemotherapy with the same regimen was then given. Sputum volume decreased slightly and arterial blood gas findings improved somewhat, but only for 2 weeks after chemotherapy. Although a third course of chemotherapy with CDDP, VDS and etoposide (VP-16) was administered, only transient improvement of respiratory distress was seen. Subsequently, inhalation therapy with 5-fluorouracil (5-FU) at a dose of $250 \mathrm{mg} \cdot \mathrm{day}^{-1}$ was administered. The productive cough persisted, and sputum volume did not decrease to less than $150 \mathrm{ml} \cdot$ day $^{-1}$.

In March 1991, erythromycin therapy at a dose of 600 $\mathrm{mg} \cdot \mathrm{day}^{-1}$ was introduced with the purpose of suppressing the production and discharge of sputum. The sputum volume was decreasing in the first few days of administration of erythromycin, and markedly decreased to almost 20-30 ml-day ${ }^{-1}$ after 10 weeks. Although a deterioration was apparent on the chest roentgenogram, the patient was discharged from the hospital with home oxygen therapy because his daily life activities had been markedly improved by the reduction of sputum volume due to erythromycin. He was able to live a good life at

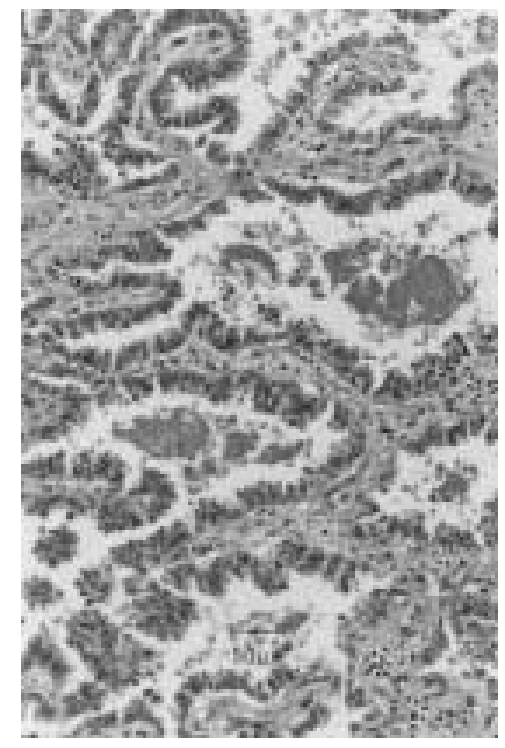

Fig. 3. - Autopsy specimen of the lung. The intact alveolar walls are lined by cells with hobnail-appearance and slight atypia. (Scale bar $=50 \mu \mathrm{m}$ ).

home until his last admission, and died three months later. An autopsy was performed, and the diagnosis of BAC confirmed (fig. 3). 


\section{Discussion}

The most common symptoms of BAC are cough, chest pain, dyspnoea, haemoptysis and sputum production. Bronchorrhoea, the production of a huge volume of watery sputum, is unusual, but a very serious problem in patients with BAC [4].

Erythromycin has recently been used for the treatment of diffuse panbronchiolitis and has produced excellent results $[5,6]$. Although its mechanism in alleviating diffuse panbronchiolitis remains unclear, some possibilities, including inhibition of hypersecretion, have been suggested. Goswami et al. [2] reported that erythromycin reduced respiratory glycoconjugate secretion in an in vitro preparation of human airways. Furthermore, they reported that a similar effect of erythromycin was observed in a human endometrial adenocarcinoma cell line which secrets a glycoconjugate. TAMAOKI et al. [3] reported that erythromycin might selectively inhibit $\mathrm{Cl}$ secretion across the airway epithelium via the inhibition of prostaglandin synthesis [3]. Since active transport of $\mathrm{Cl}^{-}$by the airway epithelium is correlated with the secretion of water, inhibition of $\mathrm{Cl}^{-}$ secretion by erythromycin might result in a decrease in the amount of water in the sputum. MAROM and Goswami [1] described a patient with severe excessive mucus secretion (bronchorrhoea) and airway obstruction, who was successfully treated with erythromycin; there was a significant reduction in the volume of mucus and a significant decrease in the intensity and frequency of asthma attacks [1].

In our patient with BAC, it is assumed that mucus and water hypersecretion from carcinoma cells was reduced by administration of erythromycin. Since hypersecretion is a very serious problem in some patients with BAC, erythromycin therapy may be worthwhile for improving the daily life activities of these patients.

\section{References}

1. Marom ZM, Goswami SK. Respiratory mucus hypersecretion (bronchorrhea): A case discussion - possible mechanism(s) and treatment. J Allergy Clin Immunol 1991; 87: 1050-1055.

2. Goswami SK, Kivity S, Marom Z. Erythromycin inhibits respiratory glycoconjugate secretion from human airways in vitro. Am Rev Respir Dis 1990; 141: 72-78.

3. Tamaoki J, Isono K, Sakai N, Kanemura T, Konno K. Erythromycin inhibits $\mathrm{Cl}$ secretion across canine tracheal epithelial cells. Eur Respir J 1992; 5: 234-238.

4. Storey CF, Knudtson KP, Lawrence BJ. Bronchiolar ("alveolar cell") carcinoma of the lung. J Thorac Surg 1953; 26: 331-406.

5. Kadota J, Sakito O, Kohno S, et al. A mechanism of erythromycin treatment in patients with diffuse panbronchiolitis. Am Rev Respir Dis 1993; 147: 153-159.

6. Kudoh S, Uetake T, Hagiwara K, et al. Clinical effect of low-dose, long-term erythromycin chemotherapy on diffuse panbronchiolitis. Jpn J Thorac Dis 1987; 25: 632-642. 